\title{
Formação das elites político-administrativas no Brasil: as instituições de pesquisa econômica aplicada ${ }^{1}$
}

\author{
Maria Rita G. Loureiro Durand
}

\section{Introdução}

Os estudos sobre elites políticas analisam tradicionalmente suas formas de atuação, suas relações com os governados (enfatizando os vínculos contidos no par elites $\mathrm{x}$ massas), o grau de autonomia com relação aos interesses econômicos, suas origens históricas, etc. (ver a respeito, além das obras clássicas de Pareto, Mosca e Michels, o trabalho de Bottomore, 1965 e mais recentemente, o do Bobbio, 1982). No Brasil, existe um número já considerável de estudos sobre diferentes segmentos das elites políticas, tais como militares, burocratas, parlamentares, etc. Eles, em geral, enfatizam suas estratégias de poder e relações com demais segmentos dirigentes. Os principais títulos nesta área são os de STEPAN (1975 e 1986), Carvalho (1986), Coelho (1985), Goes e Camargo (1984), Nunes (1978), Miceli (1981), Martins (1984), Schneider (1991) e Gouvea (1994).

O presente trabalho procura examinar a dimensão ainda pouco desenvolvida nos estudos sobre elites político-administrativas no Brasil, qual seja, o processo de sua formação prática, no interior dos organismos governamentais e não-governamentais de pesquisa aplicada e de planejamento econômico. Ele se insere num estudo mais amplo que venho desenvolvendo sobre os economistas como elites dirigentes no Brasil, e no qual procuro analisar sua constituição histórica, seus vínculos com outros segmentos das elites políticas e ainda suas relações com as instituições acadêmicas.

Analisam-se, assim, neste texto, os órgãos de pesquisa econômica aplicada, como o Ibre (Instituto Brasileiro de Economia) da Fundação Getúlio Vargas, o Ipea (Instituto de Pesquisa Econômica Aplicada), do Ministério do

Socióloga, professora do curso de mestrado em administração pública e governo, da Fundação Getúlio

Vargas de São

Paulo e do

Departamento de Economia da FEA/USP 
Planejamento, e a Fipe (Fundação Instituto de Pesquisas Econômicas) da Universidade de São Paulo. Dentre as várias instituições governamentais e não-governamentais de pesquisa econômica, estas três foram escolhidas porque constituíram, ao longo das últimas décadas, espaços importantes nos quais os economistas desenvolveram sua competência prática. Através das agências de pesquisa, essa elite pôde transformar as ferramentas e modelos teóricos adquiridos nas universidades em diagnósticos (aí incluindo a produção de estatísticas e índices) e propostas de políticas econômicas.

Contribuindo com a formação da competência técnica do economista, em alguns momentos, mais até dos que os próprios cursos universitários, os institutos de pesquisa econômica aplicada tornaram-se verdadeiros think tanks. Pode-se definir como think tank a organização independente, engajada em pesquisa multidisciplinar, que objetiva influenciar as políticas públicas (JAMES, 1993: 492). Se a independência com relação ao governo é imprescindível neste tipo de organização, suas atividades, entretanto, estão voltadas necessariamente para as demandas concretas das políticas governamentais. Suas pesquisas distinguem-se das acadêmicas no sentido estrito à medida que combinam preocupações práticas com abordagem reflexiva e perfil amplo. Nesse sentido, os think tanks acabam funcionando como intermediários entre o mundo acadêmico e o governo, como se verá nos três casos analisados a seguir. ${ }^{2}$

Embora essas organizações independentes, envolvidas em pesquisas, tenham tido difusão mais intensa nos Estados Unidos, elas são igualmente importantes em outros países. Desempenham aí papel de destaque nos debates de políticas econômicas alternativas, oferecem argumentos tecnicamente consistentes para os grupos de oposição aos governos, e preparam seus quadros para assumirem postos nas futuras administrações, como ocorreu na Inglaterra de Margareth Tatcher (JAMEs, 1993) e no Chile de Pinochet (SILVA, 1991). Analisando as razões das existências de grandes números de think tanks nos Estados Unidos - mais de uma centena, só em Washington - JAMES (1993) explica que nesse país, o recrutamento de quadros para o governo, baseado no chamado "spoil system", é menos auto-suficiente, se comparado aos padrões vigorantes em outros como a Inglaterra, França ou Japão, nos quais o corpo de burocratas permanentes é praticamente único na condução das políticas públicas. Em outras palavras, o revezamento, em todo novo governo dos Estados Unidos, gerado pelas nomeações políticas de grande parte dos quadros do alto escalão, acaba criando a necessidade de o Executivo recorrer a um círculo mais extenso e extrovertido de assessores para as diversas políticas públicas. No Brasil, como se sabe, o recurso a especialistas externos, nomeados para os altos postos governamentais, os chamados cargos em comissão, ocorre em todas as áreas de políticas públicas. $\mathrm{Na}$ área de gestão macroeconômica, são importantes para o provimento 
destes cargos os vínculos com as universidades e com os institutos de pesquisa econômica aplicada, particularmente o Ipea. Como já se indicou, em anos recentes, mais da metade do pessoal deste instituto estava cedido a outros órgãos da administração pública (MATOs, 1994: 12).

No caso brasileiro ainda, os think tanks, como os institutos de pesquisa aqui analisados, desempenharam ainda outro papel político crucial: eles permitiram, de forma direta ou indireta, a produção da visibilidade dos economistas fora dos meios acadêmicos e sua legitimidade enquanto interlocutores políticos. Isso se deu através da discussão (ou tradução) na imprensa do significado dos indicadores econômicos produzidos e suas eventuais repercussões sobre a economia. Basta observar que quase diariamente aparecem nas primeiras páginas dos jornais os índices produzidos pela Fipe de São Paulo ou pela FGV do Rio, bem como as análises e implicações daí decorrentes, efetuadas por seus respectivos diretores-economistas. Ainda que em menor intensidade, também aparecem na imprensa, divulgando sua imagem e de seus economistas, os estudos ou debates elaborados pelo Ipea acerca de assuntos polêmicos contidos nas políticas econômicas e sociais do governo. Também outras instituições de pesquisa como o IBGE (Instituto Brasileiro de Geografia e Estatística) e o Dieese (Departamento Intersindical de Estatística e Estudo Sócio-Econômicos) têm tido destaque nos meios de comunicação sempre que os índices de custo de vida ou da cesta básica são questionados por sindicatos e outros grupos de interesse na sociedade. O que aporta, da mesma forma, notoriedade e legitimidade política para a instituição e para o respectivo economista que chefia a equipe de pesquisa.

A noção de legitimidade é entendida aqui como o reconhecimento e a aceitação (pelos meios políticos, pela mídia e pela sociedade mais ampla) do economista como ator político e de sua competência em produzir diagnósticos e gerar soluções para os problemas econômicos do País. Cabe observar que este não é um processo que decorre automaticamente da consolidação da profissão ou mesmo da expansão de práticas de intervenção e regulação do Estado na economia. Reforçam essa afirmação os casos de países como a França e o Japão, nos quais as políticas econômicas são conduzidas por burocratas generalistas sem qualquer formação específica em matéria econômica, ou de outros, como Estados Unidos e Inglaterra, em que os economistas não exercem atividades dirigentes nos organismos governamentais, mas apenas assessoram os políticos eleitos. Supõe-se aqui, ao contrário, que o processo que permitiu a emergência dos economistas como interlocutores políticos e mesmo sua ascensão à condição de segmento importante das elites dirigentes, em países como o Brasil e outros da América Latina, está associado a trabalho de construção institucional, realizado ao longo de várias décadas por inúmeras pessoas e grupos, nos meios governamentais e acadêmicos (LOUREIRO, 1997). 
Todavia, o fator essencial para a compreensão do papel assumido pelos institutos de pesquisa aplicada e pelos economistas no governo deve ser buscado nas características do sistema político brasileiro e de sua estrutura administrativa. Como a literatura tem mostrado, as relações de poder no Brasil organizam-se historicamente através de um aparelho estatal forte e de mecanismos de representação frágeis. Neopatrimonialismo e sua contraface de clientelismo e cooptação, ausência de grupos autonomamente organizados na sociedade e a conseqüente fragilidade da estrutura partidária constituem os traços centrais do autoritarismo brasileiro e as bases de sua estrutura burocrática. Conseqüentemente, a máquina administrativa constitui-se como espaço onde se manifestam as relações clientelistas de troca de favores - cargos, subsídios, encomendas públicas, etc. - por apoio político. (SouZA, 1976 e SchwartzMAn, 1988).

Como o estado brasileiro assumiu, especialmente a partir dos anos 1930/40, a tarefa de desenvolver a economia e modernizar a sociedade, houve a necessidade de se criar — paralelamente à administração organizada pela lógica clientelista - uma outra estrutura burocrática. Encarregada da condução das políticas desenvolvimentistas e devendo atender às demandas geradas pela expansão das funções reguladoras e intervencionistas do Estado na vida econômica e social, a "administração paralela" orientou-se, ao contrário da máquina clientelista, pelo critério da competência técnica e eficiência administrativa (GEDDEs, 1990 e NunEs, 1997). Agências como BNDE, Banco Central, Ipea, além de várias empresas estatais são exemplos expressivos dessas chamadas "ilhas de excelência". Por razões diversas, em nenhuma dessas duas estruturas administrativas generalizaram-se mecanismos institucionalizados de formação, recrutamento e carreira para a alta burocracia governamental (MARTINS, 1985 e SCHNEIDER, 1991), senão em setores bem específicos e autonomizados, como os militares (COELHO, 1976) e os diplomatas (CHEILUB, 1985). Assim, as instituições de pesquisa aqui estudadas acabaram exercendo, na prática, tais funções para a área de gestão das políticas econômicas.

Em suma, considerando que as instituições (como regras e organizações) desempenham papel fundamental na estruturação da vida em sociedade, moldando as ações dos indivíduos e grupos e determinando seus resultados concretos (JEPPERSON, 1991), o presente estudo procura mostrar que os institutos de pesquisa aplicada contribuíram para o desenvolvimento da competência prática dos economistas, para sua transformação em interlocutores políticos e tornaram-se, assim, espaços sociais nos quais estes profissionais se prepararam para assumir postos de destaque no governo, como importante segmento da alta burocracia governamental.

O texto a seguir compõe-se de quatro partes: a primeira refere-se à história institucional do Ibre; a segunda e a terceira, respectivamente, ao 
Ipea e à Fipe. Por fim, são apresentadas algumas considerações gerais

extraídas do exame dos três casos. Os dados que serviram de base para a análise foram levantados em entrevistas, documentos e estudos sobre cada um dos institutos analisados. Para o caso do Ipea, foram utilizados ainda os depoimentos de seus dirigentes, colaboradores e funcionários, gravados em vídeos, por ocasião das comemorações de seus 25 anos de existência. ${ }^{3}$

\section{Instituto Brasileiro de Economia da Fundação Getúlio Vargas (Ibre-FGV)}

Em 1946, foi criado, dentro da Fundação Getúlio Vargas (FGV), no Rio de Janeiro, um núcleo de economia que se transformou, em 1951, em Instituto Brasileiro de Economia - Ibre. Como se sabe, a FGV foi fundada em 1944, por iniciativa de altos funcionários do primeiro governo Vargas, ligados ao Departamento Administrativo do Serviço Público Dasp. Em particular, ela está ligada à figura do diretor-geral do Dasp, Simões Lopes, que se tornou seu presidente. O objetivo da FGV era a formação de quadros administrativos necessários à modernização do Estado; entretanto, logo no início das atividades, estabeleceu-se um redirecionamento de seus rumos, acrescentando à dimensão administrativa, os estudos e investigações econômicas, que acabaram tornando-se o carro-chefe da instituição.

Os mentores e dirigentes do Ibre, em suas primeiras décadas de existência, foram Eugênio Gudin e Otávio Gouveia de Bulhões. Figuras de destaque nos meios governamentais, acadêmicos e empresariais da época, Gudin e Bulhões trouxeram prestígios e reconhecimento imediato à instituição. Além de ministros da Fazenda, eles haviam participado, desde os anos 30 e 40, de numerosas comissões econômicas governamentais no Brasil, encarregadas de elaborar diagnósticos e propostas de políticas para diferentes áreas da economia e de reuniões internacionais, como a de Bretton Woods, que criou o FMI; além de atuarem em conselhos de administração de numerosas empresas privadas nacionais e estrangeiras, tinham ainda envolvimento com projetos universitários que visavam à criação de cursos de economia no Brasil. (LOUREIRO, 1997).

Dentre as atividades do Ibre, podem-se mencionar como as mais relevantes o trabalho de preparação do balanço de pagamentos, a construção do sistema de contas nacionais e a criação de índices econômicos. Estas atividades distinguiram-se pelo caráter pioneiro e inovador. Como se sabe, o balanço de pagamentos e as contas nacionais - estatísticas necessárias à implementação das políticas macroeconômicas de inspiração keynesiana — foram implantados no Brasil já no final dos anos 40, o que representava um avanço em relação a vários países desenvolvidos. No tocante aos índices de preços, deve-se lembrar que estes indicadores, 
fundamentais em economias estruturalmente inflacionárias, como a bra-

sileira, permitiram o estabelecimento, anos mais tarde, do instituto da correção monetária. Apesar de seus efeitos econômicos perversos, esse mecanismo teve impactos políticos importantes: o recurso da indexação generalizada permitiu a convivência da economia brasileira com períodos de altas e crônicas inflações sem a geração de uma grande crise hiperinflacionária e constituiu-se, do ponto de vista político, num eficiente mecanismo institucional de acomodação de conflitos distributivos (Sola e KugELMAs, 1996: 401). Em outras palavras, através do Ibre foram desenvolvidos os instrumentos necessários para a produção de informações e a análise econômica que os órgãos governamentais ainda não possuíam e que se tornavam cruciais para a regulação e o planejamento econômico, crescentemente implementados pelo Estado naquele momento.

Além dos diversos centros, compunham, ainda, as atividades do Ibre a publicação de revistas especializadas e a manutenção de um núcleo de ensino de ciência econômica pela instituição, como o CAE (Centro de Aperfeiçoamento de Economistas) que se transformou, em 1966, na atual Escola de Pós-graduação em Economia (EPGE).

Para o desenvolvimento destas atividades, este instituto estabeleceu, desde sua criação, vínculos estreitos com os meios acadêmicos nacionais e estrangeiros, enviando sistematicamente seus membros para estágios no exterior, e recebendo pesquisadores visitantes dos Estados Unidos e Europa, como G. Haberler, N. Kaldor, G. Myrdal, R. Nurkse, Raul Prebisch, J. Viner, etc. Através do envio sistemático de seus quadros para estágios no exterior e da presença freqüente de professores estrangeiros, a instituição assumiu caráter marcadamente acadêmico e cosmopolita, definindo-se como centro divulgador das informações científicas e técnicas trazidas de outros países.

Além dos vínculos com os meios universitários nacionais e estrangeiros, destaque especial deve ser dado às relações do Ibre com os organismos governamentais. Embora entidade de direito privado, a FGV construiu, desde seu nascimento, estreitos laços com o Estado, definindo-se como instituição formadora de quadros de nível superior para a administração pública e, assumindo, logo em seguida, com o Ibre, a tarefa de produzir informações básicas para orientar a tomada de decisão nas agências governamentais de planejamento e regulação econômica. E, naturalmente, recebeu recursos públicos para financiar tais atividades. Além disso, havia um intercâmbio intenso entre agências governamentais e o Ibre, através de trabalho conjunto ou simultâneo de seus membros. Na verdade, pode-se indicar a existência de uma rede de relações interpessoais que interconectava este instituto, a Faculdade Nacional de Ciência Econômica, da então Universidade do Brasil e diversos órgãos governamentais de gestão econômica, como o Ministério da Fazenda, o Banco do Brasil, a Sumoc, o IBGE, etc. 
Em suma, o Ibre constituiu, durante as primeiras décadas de sua história institucional, o pólo mais importante de produção e divulgação de conhecimento econômico no Brasil, e o espaço onde a ciência econômica assumiu sua dimensão prática, afirmando-se como requisito básico de competência para a condução de políticas econômicas no país. Entretanto, esta situação se alterou nos últimos tempos. Analisando-se a longa trajetória institucional do Ibre, podem-se identificar três momentos distintos.

O primeiro momento, de formação e consolidação, estende-se até 1964. Além das estreitas relações com os meios acadêmicos e organismos governamentais, foram característicos deste período os vínculos estabelecidos com organismos internacionais que aportavam recursos financeiros e conhecimento técnico para os pesquisadores do instituto, através de contratos de pesquisa. Vários depoimentos indicam a importância, por exemplo, dos acordos de cooperação com a Fundação Rockefeller e o Departamento de Agricultura do governo americano, para o financiamento de pesquisas. Dentre elas, pode-se citar o estudo sobre a agricultura brasileira, realizada no início dos anos 60 , a qual deu origem posteriormente ao Centro de Estudos Agrícolas do Ibre. Indicam-se ainda as relações da FGV com organismos como a Fundação Ford e a Usaid, que permitiram, através da concessão de bolsas de estudos e de outros recursos financeiros, o surgimento do Centro de Aperfeiçoamento de Economistas (CAE), posteriormente transformado na atual Escola de Pós-graduação em Economia (EPGE). Como se sabe, estes centros foram responsáveis pela formação de numerosos economistas brasileiros no próprio país e no exterior, em particular, nos Estados Unidos.

Os anos 60 e 70 podem ser considerados como a fase de apogeu das atividades do Ibre. Ela se associa aos primeiros governos militares, em particular, à passagem pelo governo de vários de seus membros, como Otávio Gouveia de Bulhões, Roberto Campos, Mário Henrique Simonsen, e outros, como Carlos Langoni. Não só os contratos, as encomendas e, conseqüentemente, os recursos públicos eram estáveis e abundantes neste período, mas também os efeitos de prestígio e visibilidade dos ministros de Estado e ocupantes de outros postos de relevo recaíam positivamente sobre a imagem e o reconhecimento da instituição.

A partir do final dos anos 80, dois fatores explicam o declínio e a reorientação mais recente do Ibre. O primeiro, e mais importante, tem a ver com a crise do Estado brasileiro e os cortes nas subvenções governamentais que geraram impactos consideráveis sobre o orçamento da Fundação Getúlio Vargas. Diante da enorme redução das verbas públicas, essa instituição passou por intenso processo de reestruturação interna, que levou à demissão de grande número de funcionários, extinção de órgãos e a reorientação de suas atividades, em vista à geração de receita própria. Isso atingiu particularmente o Ibre que, de órgão tradicionalmente produtor 
de estatísticas econômicas para agências públicas (através de dotações governamentais) passou para a condição de entidade produtora de informações vendidas ao mercado.

O segundo fator está relacionado ao primeiro e tem a ver com a perda gradativa do papel do Ibre como produtor de estatísticas oficiais. Com a criação do Banco Central, a elaboração do balanço de pagamentos passou para este órgão e, a partir de 1985, as contas nacionais foram transferidas para o IBGE. A recusa em atender demandas do governo para alterar os índices de preços permitiu que o Ibre fosse identificado como instituição independente e, portanto, ganhasse confiabilidade por parte do mercado de clientes privados que demandam seus serviços estatísticos.

Hoje, as atividades centrais do Ibre restringem-se à produção de estatísticas econômicas (os índices de preços e, mais recentemente, com a estabilização monetária, os índices de custos setoriais) vendidas para empresas privadas e estatais ou mesmo órgãos públicos. ${ }^{4} \mathrm{~A}$ infra-estrutura montada ao longo dos anos, em vários estados da federação para a coleta de informações, a competência técnica aí acumulada e a confiança em sua atuação independente são, segundo seus membros, os principais trunfos acionados pelo Ibre diante de seus competidores, em particular IBGE, Fipe e mesmo Dieese.

Estas mudanças, associadas ao surgimento de outros importantes institutos de pesquisa econômica, fizeram com que o Ibre perdesse seu papel histórico de centro de produção e divulgação de conhecimento em economia e espaço privilegiado de formação prática e mesmo teórica para economistas. Tornando-se, predominantemente, produtor de índices de preços e de custos, seus profissionais não são mais hoje, de forma majoritária, como no passado, economistas e sim diplomados em matemática, estatística ou econometria. Estes trabalham em tempo integral, sem vínculos com as universidades, são absorvidos em sistemas internos de gratificação por desempenho e produtividade; portanto, movidos pela lógica competitiva como qualquer outra empresa privada.

Diante de tais transformações, alguns dos membros mais antigos apontam a profunda crise de identidade vivida pelo Ibre, e indagam se ele poderá recuperar seu antigo papel de instituição pioneira e inovadora na produção de estudos e de estatísticas econômicas, como bens públicos, ou se consolidará como uma simples agência de consultoria, produtora de serviços privados vendidos no mercado. A ausência de lideranças como as do passado, estreitamente vinculadas a organismos governamentais e meios acadêmicos e a emergência de novas instituições, como o Ipea, por exemplo, que desenvolvem de forma sistemática e intensiva a pesquisa econômica, são desafios enormes e talvez insuperáveis. 


\section{O Instituto de Planejamento Econômico e Social da Se- cretaria de Planejamento e Coordenação da Presidência da República - Ipea/Seplan}

As origens deste órgão remontam ao final do governo Goulart, quando foi criada a Associação Nacional de Programação Econômica e Social (Anpes), com o objetivo de "realizar estudos para o desenvolvimento de planos para governos futuros", conforme indicou Mário Henrique Simonsen, em depoimento gravado por ocasião das comemorações dos 25 anos do Ipea. Esta associação privada, financiada por vários empresários, sobretudo de São Paulo, era dirigida por um grupo constituído por Roberto Campos, Mário Henrique Simonsen, Vitor da Silva e, posteriormente ampliado com outros nomes, dentre eles, o de Reis Velloso que havia, na época, acabado de chegar dos Estados Unidos com um diploma de mestrado por Yale. Com a ascensão de Campos ao cargo de ministro do Planejamento, no primeiro governo militar, decidiu-se que este grupo, que já estava elaborando as propostas iniciais do Paeg (Plano de Ação Estratégica do Governo), se transformasse em órgão da própria estrutura governamental. Foi assim criado, em setembro de 1964, o Epea - Escritório de Pesquisa Econômica Aplicada, com a missão de efetuar estudos e pesquisas necessárias ao planejamento econômico.

$\mathrm{Na}$ verdade, a idéia de se formar uma agência governamental de planejamento já havia sido objeto de várias discussões de Campos e Bulhões com dirigentes da Fundação Getúlio Vargas e altos funcionários do governo americano, tais como o embaixador Lincoln Gordon e o diretor da Usaid no Brasil. A partir destes encontros, decidiu-se que a Usaid faria contatos em universidades nos Estados Unidos para trazer ao novo órgão de planejamento do governo brasileiro a competência técnica que faltava ao País. O professor Higgins, da Universidade do Texas, foi o primeiro economista americano a colaborar com o Epea, que, neste período, concentrava-se no processo de formulação do Paeg. Muitos outros professores americanos vieram, anos depois, e tornaram-se figuras conhecidas nos meios acadêmicos, como foi o caso de Albert Fishlow, envolvido com o debate sobre distribuição de renda, nos anos 70. Cabe destacar, ainda, no contexto inicial de constituição do Epea, os intensos vínculos de trabalho estabelecido com organismos internacionais, ou seja, a chamada “invasão de missões estrangeiras", originárias de organismos como o OEA, FMI, do BIRD, BID, Eximbank, Secretaria do Tesouro americano, etc. (Ver a respeito, CARvalHo, 1996).

Com relação aos objetivos pensados para o Ipea no momento de sua criação, Reis Velloso - seu primeiro dirigente e patrono durante vários anos - indica, também, em depoimento prestado por ocasião dos 25 anos deste órgão, que eles não estavam tão claros para seus construtores. Havia 
apenas a certeza de que não se deveria criar uma outra Fundação Getúlio Vargas, isto é, uma instituição acadêmica. Daí, a caracterização de instituto de pesquisa aplicada, voltado para as necessidades imediatas exigidas pelas políticas governamentais. Aos poucos, a idéia de constituição de um "think tank", isto é, de um órgão pensante dentro do próprio governo, no qual se formularia, através de estudos sistemáticos e debates constantes dos problemas nacionais, a visão estratégica para o País, foi tomando forma e se consolidou com a própria transformação do Epea em Ipea, em 1967, no bojo do Decreto ํㅡ 200 da reforma administrativa. Segundo ainda palavras do próprio Reis Velloso, com o Ipea institucionalizou-se o planejamento governamental no Brasil, mas este era visto menos como uma metodologia e mais como um núcleo provedor de idéias para a sociedade.

Dentre as atividades desenvolvidas, cabe destaque para a elaboração dos planos econômicos governamentais, como o Paeg, já citado, o Plano Decenal de Desenvolvimento Econômico e Social (1967-1976) — única iniciativa, como já se indicou, de planejamento de longo prazo no Brasil, o Plano Nacional de Desenvolvimento (PND) do governo Geisel e outros (CAvalcanti, 1989). Para o desenvolvimento destas atividades de planejamento, o Ipea atuou também na formação de técnicos, não apenas na esfera federal, mas também na estadual e municipal, através do Cendec (Centro de Treinamento para o Desenvolvimento Econômico). Através deste, grande número de profissionais, economistas, engenheiros, estatísticos e outros, vindos de diversas regiões do País, foram capacitados para as atividades de planejamento econômico e social, sendo que muitos deles foram posteriormente recrutados para o trabalho na própria instituição.

Todavia, mais do que as próprias atividades de planejamento, o Ipea teve papel crucial na produção de conhecimento econômico no País, através de suas atividades sistemáticas de pesquisas aplicadas tanto em áreas macroeconômicas quanto em áreas setoriais e sociais - agricultura, indústria, tecnologia, desenvolvimento regional, energia, mercado de trabalho, educação, saúde, previdência e outras. Levantamentos indicam que nos seus 25 primeiros anos de existência, 3.421 trabalhos foram aí produzidos, entre livros, artigos, monografias e relatórios. A revista "Pesquisa e planejamento econômico", editada também pelo Ipea, é considerada nos meios acadêmicos uma das mais importantes do País.

Aliás, os vínculos deste órgão governamental com os meios universitários foram intensos, manifestando-se em diferentes situações, tais como, o trabalho concomitante dos técnicos do Ipea em universidades, o envio sistemático de seus membros para programas de doutoramento ou especialização no exterior, a acolhida de professores universitários estrangeiros e nacionais para assessorar as pesquisas em realização e 
ainda o financiamento das atividades da Anpec (Associação Nacional de Pós-Graduação em Economia). As relações com a Anpec, mantidas até hoje, concretizam-se através da transferência de recursos para a realização de seu encontro anual ou outros seminários especiais, onde os pesquisadores do Ipea têm expressiva participação em quase todas as mesas ou grupos de trabalho, para a realização de pesquisas e no passado, até para bolsas aos estudantes de pós-graduação dos diversos centros filiados àquela associação. Estes vínculos permitiram a configuração de um perfil bastante acadêmico para o Ipea, que se transformou, ao longo dos anos 70, em um dos espaços mais importantes de produção de conhecimento e de debate econômico no País. Segundo depoimento da economista Maria Conceição Tavares, na ausência de outros canais de discussão, durante a ditadura militar, e ancorados na proteção do ministro Reis Velloso, os economistas das mais diversas correntes de pensamento, trabalhando ou não no Ipea, encontraram aí, em seus seminários regulares, o principal fórum de discussão dos problemas do País.

Se as atividades de pesquisas, publicações e debates geraram para o Ipea renome e prestígio nos meios acadêmicos nacionais e estrangeiros, tornando este órgão governamental referência necessária para a produção de conhecimento econômico no Brasil, o mesmo não pode ser dito com relação às suas atividades de planejamento. Estas, na verdade, foram objetos de orientações divergentes por parte dos ministros do Planejamento.

De um lado, pode-se indicar a visão de Velloso, construída num quadro de extremado centralismo decisório, fundamentada em crença fervorosa, nas possibilidades de um órgão governamental produzir idéias estratégicas para a Nação; que, ainda, imaginava ser necessária e desejável a institucionalização do planejamento, como um sistema nacional de coordenação das políticas públicas e prática regular difundida por todos os poros do governo. Assim, a crença de Velloso o levou não só a prestigiar o Ipea, mas sobretudo a considerar os estudos aí efetuados como inputs fundamentais para a elaboração das políticas econômicas e sociais sob sua direção.

De outro lado, a visão de Delfim Neto era bastante cética a esse respeito. Ao contrário de Velloso, Delfim Neto descaracterizou o Ipea como órgão formulador de políticas econômicas. Talvez por contar com o apoio de uma equipe técnica de sua confiança pessoal — constituída de colegas e ex-alunos da Universidade de São Paulo — que ele levou consigo para os cargos de gestão econômica em Brasília, Delfim pôde prescindir da assessoria institucional do Ipea, órgão que ele mal conhecia e pouco valorizava. Mas o argumento mais consistente, explicando a posição do ministro Delfim pode ser encontrado na posição assumida pelo Ipea de principal reduto de críticas ao chamado "milagre econômico" e suas implicações sobre o agravamento da concentração da renda no País. 
Apesar das divergências entre os ministros com relação ao papel a ser atribuído ao planejamento e ao Ipea, cabe observar que esta instituição acabou funcionando como canal importante para seus economistas de alavancagem de carreira a altos postos dirigentes nas agências de gestão econômica do governo. Como indicou um comentarista, durante as comemorações de seus 25 anos, não é por acaso que “desde 1964, nove 'ipeanos' chegaram a ministro e, no mínimo, 16 emplacaram uma secretaria-geral (segundo cargo de importância na burocracia ministerial) e uma infinidade de técnicos menos afortunados ocupou a periferia dos gabinetes oficiais" (O Estado de S. Paulo, 10/9/1989, p.9). Se atualizarmos este balanço, ele poderá ser acrescido de muitos outros nomes de ministros, como o de Pedro Malan, Dorothéa Werneck, etc.).

Do ponto de vista da história institucional do Ipea, é possível identificar dois momentos bastante distintos. Se o primeiro, que vai de seu surgimento até o final dos ano 70, pode ser definido como período de apogeu de suas atividades e no qual ele ocupou lugar de destaque na produção de conhecimento e nos debates econômicos, no País, o segundo momento é de profunda crise institucional. Esta emerge, como se pode imaginar facilmente, a partir dos anos 80, com o declínio da prática de planejamento, associado à grande crise econômica e do Estado e à emergência do discurso neoliberal. Tal situação atinge sua fase mais aguda durante o governo Collor, manifestando-se na redução drástica de recursos financeiros para a manutenção das atividades básicas da instituição no Rio e em Brasília, na queda vertiginosa dos salários e na saída de grande parte de seus técnicos.

Se o desmonte da instituição não se efetivou completamente, isso se deveu a iniciativas de seus dirigentes que conseguiram acionar convênios de pesquisa com organismos internacionais como o PNUD, do Banco Mundial e com outros órgãos do governo, como a Fundação Banco do Brasil. Com estes convênios, que aportaram à instituição recursos sob a forma de material de consumo para o desenvolvimento das pesquisas, alguns computadores e o pagamento, de forma indireta, de auxiliares de pesquisas, o Ipea pôde manter-se funcionando, minimamente, nos tempos mais difíceis.

A partir dos dois últimos anos, observa-se a revitalização da instituição através de seu reaparelhamento físico e da contratação, ainda que gradual, de novos técnicos. Todavia, esse processo aparece de forma mais significativa na retomada do papel histórico do Ipea de assessoria técnica do Ministério do Planejamento, a partir das gestões de José Serra e Antônio Kandir, no governo Fernando Henrique Cardoso. Segundo depoimentos, os técnicos do Ipea têm sido chamados para discussão de temas macroeconômicos, setoriais e sociais, em reuniões 
semanais no ministério. Como exemplo deste envolvimento, pode ser citado o caso dos estudos solicitados ao Ipea sobre os impactos da desoneração de ICMS sobre produtos exportados, no segundo semestre de 1996, que serviram de base para a formulação da nova política. O traço particular que diferencia a assessoria do Ipea das demais fornecidas pelos ministérios é seu caráter independente. Hoje, como foi no passado, afirmam seus técnicos, o governo não interfere na produção de conhecimento gerada neste instituto. Em outras palavras, as agências governamentais apenas solicitam as informações e análises produzidas pelo Ipea e as utilizam ou não conforme suas conveniências políticas, não impedindo inclusive a publicação de visões eventualmente contrárias a suas orientações.

Os indicadores de revitalização não podem, porém, ser vistos como definitivos. Isto é, há desafios a serem ainda superados, para que o Ipea se transforme numa instituição consolidada de assessoria técnica governamental de alto nível. Eles abrangem desde os obstáculos administrativos de contratação e gestão de recursos humanos até a questão mais profunda, que envolve a fragilidade institucional do País.

De um lado, o regime jurídico único trazido pela Constituição de 1988 impede a flexibilidade de práticas de recrutamento, promoção e demissão de técnicos e demais funcionários em função de desempenho e qualidade na produção de pesquisas econômicas. De outro lado, as atividades de assessoria ao Ministério do Planejamento estão freqüientemente sujeitas a contingências e ao peso político dos ministros do planejamento no conjunto do governo. Se o ministro é forte, participa ativamente das políticas macroeconômicas e tem confiança pessoal nos técnicos do Ipea, esta instituição é acionada. Se, ao contrário, o ministro não participa de forma decisiva das políticas macroeconômicas, com foi o caso mais recente de Beni Veras, o Ipea fica marginalizado de sua função de assessoria técnica. Além disso, se o ministro tem sua própria equipe de assessores e não confia no Ipea, seja por orientações teóricas - como foi o caso de Delfim nos anos 70 e 80 - ou seja, porque percebe crise ou descoordenação interna do órgão como ocorreu no período do ministro João Sayad, o Ipea não é acionado.

Em suma, o Ipea pode ser visto, de um lado, como a instituição mais importante do País, nas últimas décadas, de produção sistemática de pesquisas econômicas aplicadas (isto é, elaboradas como base para a formulação de políticas públicas) e, conseqüentemente, espaço de preparação de quadros para postos dirigentes na área de gestão econômica do governo. De outro lado, porém, suas vicissitudes revelam, mais uma vez, a fragilidade das instituições no País, que dependem de contingências ou da patronagem pessoal. 


\section{Instituto de Pesquisas Econômicas da Faculdade de Economia e Administração da Universidade de São Paulo - IPE/Fipe/FEA/USP}

Fundado em 1964, como órgão de apoio ao Departamento de Economia da USP, os objetivos estabelecidos para o IPE, desde seu início, desenvolveram-se em torno da realização de pesquisas, promoção de cursos, seminários e estudos necessários à melhoria do ensino de economia, da divulgação do conhecimento nesta área e ainda da colaboração com instituições privadas e públicas em programas de desenvolvimento econômico e social. Além disso, como tarefa especial, ele se encarregou de organizar e implantar o programa de pós-graduação em economia na Universidade de São Paulo.

Para a realização destas atividades, o IPE contou com importante ajuda originária de convênios com organismos americanos, especialmente para o desenvolvimento do curso de pós-graduação. Como a FGV do Rio de Janeiro, que na mesma época, iniciava seus cursos de formação pós-graduada para economistas, a FEA/USP também recebeu recursos da Usaid-Brasil, da Cooperação Técnica da Aliança para o Progresso e da Fundação Ford destinados a manter os salários de professores brasileiros em treinamento nos Estados Unidos e a acolher professores americanos que vieram ao Brasil prestar assessoria ao curso de pós-graduação, nas atividades de desenvolvimento de currículo, planejamento de pesquisas, avaliação do aproveitamento dos alunos e outras. O IPE contou também com a colaboração financeira do BID, para a realização de cursos de especialização destinados ao pessoal de bancos de desenvolvimento. Além dos recursos financeiros vindos de agências estrangeiras, foram estabelecidos convênios com organismos do governo brasileiro, tanto no nível federal (BNDE) quanto no nível do governo do Estado de São Paulo e da Prefeitura Municipal (Secretarias de Planejamento, da Fazenda, Comissões de desenvolvimento regional, etc.).

A partir de meados dos anos 70, o término dos convênios com organismos internacionais e a necessidade de maior flexibilidade para o estabelecimento de contratos com outras instituições fizeram com que, além do IPE, fosse criado outro órgão, a Fundação Instituto de Pesquisas Econômicas Fipe. Como fundação de direito privado, a nova instituição pôde contratar, mais agilmente, os serviços de pesquisa e consultoria junto a organismos públicos e empresas privadas. Os recursos trazidos agora de forma mais abundante e regular pela Fipe são alocados para o desenvolvimento das atividades do IPE - hoje encarregado, com o departamento de economia, exclusivamente pelo curso de pós-graduação - e para as pesquisas e publicações dos professores do departamento de economia, além do overhead, destinado por regulamento, à própria faculdade e à universidade. 
Dentre as atividades desenvolvidas pela Fipe, cabe destaque para a elaboração de índices econômicos, para os cursos regulares de extensão universitária destinados a profissionais de empresas e organismos públicos em programas de reciclagem nas áreas econômico-financeiras e as publicações, que vão desde revistas acadêmicas, relatórios de pesquisas até boletins mensais. Com relação aos índices de preços, eles são elaborados por equipe própria dentro da Fipe, através de recursos originários de contratos efetuados com organismos governamentais e empresas privadas, tais como a Secretaria de Finanças do Município de São Paulo, que financia o Índice de Preços ao Consumidor (IPC-Fipe), a Secretaria dos Negócios da Fazenda do Estado de São Paulo, que encomenda o Índice de Custo de Construção de Obras Públicas(ICC-SP), a Associação Brasileira da Indústria de Base, que contrata o Fipe-ABDIB e muitos outros. É importante ainda enfatizar as pesquisas desenvolvidas pela Fipe, que geraram subsídios para políticas econômicas na área agrícola, monetária, de finanças públicas, de relações de trabalho, etc (ver a respeito documentos da Fipe/USP).

Pensando em termos comparativos, observa-se que a Fipe se assemelha ao Ibre e ao Ipea, em vários pontos e, em outros, se diferencia deles. Assim, a Fipe atua, da mesma forma que o Ibre hoje, como grande unidade de consultoria e prestação de serviços contratados de forma competitiva no mercado. Todavia, como instituições ligadas a meios acadêmicos, elas duas distinguem-se de uma simples empresa privada de consultoria, porque gozam de posição privilegiada, em dois pontos importantes. Em primeiro lugar, estão dispensadas de licitação pública em seus contratos, já que consideradas de notório saber; em segundo lugar, mas não menos importante, dispõem de uma reserva potencial de recursos humanos competentes e diversificados, para os quais não têm de fazer investimentos prévios, constituída pelo corpo docente de seus respectivos núcleos universitários: a Faculdade de Economia e Administração da USP para a Fipe e para o Ibre, a Faculdade Nacional de Ciências Econômicas da antiga Universidade do Brasil, no início de suas atividades e posteriormente, a Escola de Pós-Graduação em Economia (EPGE/FGV). Neste sentido, os vínculos entre os meios acadêmicos de economia e os institutos de pesquisa aplicada reforçam-se e complementam-se mutuamente, ocorrendo um processo de otimização dos custos de oportunidade dos recursos utilizados.

Outro ponto de semelhança da Fipe com o Ibre e demais centros universitários de pesquisa, como a Fucamp (Fundação Universidade de Campinas), pode ser encontrado no aumento ou redução dos contratos com órgãos públicos determinados pela presença ou não de ex-membros destes institutos em cargos governamentais, tanto na esfera federal quanto na estadual. 
Por outro lado, diferenciações começam a ocorrer com relação ao Ibre. Como já se indicou anteriormente, o Ibre tem restringido, em anos mais recentes, seus vínculos com os meios universitários e com a EPGE em particular, contratando para trabalho em tempo integral profissionais estatísticos e matemáticos, mais do que economistas, à medida que se afasta da produção de conhecimento econômico propriamente dito e assume tarefas predominantemente voltadas para a produção de índices. Com relação ao Ipea, cabe relembrar que se, de um lado, ele mantém vínculos estreitos com os meios universitários, de outro lado, seus pesquisadores não necessitam de disputar no mercado fontes de financiamento através da propostas de temas "vendáveis" para seus potenciais compradores. Os recursos públicos alocados de forma regular, mesmo que escassos, garantem uma produção sistemática de pesquisas cujos temas são de conveniência dos organismos do governo federal e também do interesse acadêmico dos pesquisadores do Ipea.

Porém, a despeito das diferentes lógicas que movimentam as atividades destes institutos, todos eles acabam desempenhando um papel importante na formação prática do economista, transformando seu saber acadêmico em competência para formular problemas de investigação que interessem a suas clientelas externas (órgãos do sistema federal de planejamento como é o caso do Ipea ou empresas e organismos públicos como são os clientes do Ibre e Fipe). A Fipe, por outro lado, tem assumido também importante papel de financiador (em complementação aos órgãos tradicionais de financiamento como CNPq, FAPESP, etc.) das atividades de pesquisa dos professores do departamento de economia da FEA/USP, além de oferecer prêmios em dinheiro para estimular suas publicações em livros e revistas nacionais ou estrangeiras.

Com relação à história institucional do IPE/Fipe, o ponto de inflexão que separa dois momentos distintos foi a criação da Fipe, em 1974, por razões já indicadas. No conjunto de sua trajetória de expansão e consolidação, é preciso observar que as situações de maior ou menor dinamismo coincidem com a presença ou não de seus membros em cargos governamentais, no nível federal ou estadual. O que, aliás, parece ser a tônica para todas as instituições de pesquisa, como já foi apontado para o caso do Ibre também.

Por fim, cabe mencionar aqui também a relação entre a passagem pelos institutos de pesquisa e a ascensão de seus quadros dirigentes aos postos nos organismos governamentais. Como já foi citado anteriormente para os casos do Ibre e do Ipea, também a participação na Fipe constituiu-se como canal de alavancagem de carreira para vários de seus membros a postos de relevo no governo. Assim, não deve ser considerado como mera coincidência o fato de que Delfim Neto tenha sido um dos primeiros dirigentes do IPE/Fipe, pouco antes de se tornar secretário da 
Fazenda de São Paulo e, posteriormente, ministro do Fazenda. Também João Sayad foi vice-diretor da Fipe entre 1981-82, pouco antes de ocupar a Secretaria do Planejamento do governo Montoro e em seguida, o Ministério do Planejamento. Além desses, podem-se indicar ainda várias figuras que passaram pela direção do IPE/Fipe e, posteriormente, ocuparam cargos em agências governamentais, tais como: Afonso Celso Pastore, Ruy Leme de Aguiar, Carlos Antonio Rocca, Miguel Colassuono, Ibraim Eris, Zélia Cardoso de Melo, Roberto Macedo e muitos outros.

\section{Considerações finais}

O presente texto procurou mostrar o papel desempenhado pelas instituições de pesquisa na formação das elites político-administrativas encarregadas da gestão econômica governamental e, ainda, como contribuíram para a transformação dos economistas em importantes interlocutores políticos no País. Dois aspectos fundamentais devem ser retidos nesta análise.

Como think tanks, isto é, agências independentes de pesquisa, produtoras de conhecimento destinado a subsidiar políticas governamentais, estes institutos caracterizam-se como espaços intermediários entre o mundo acadêmico e o governo. Portanto, suas ligações com os meios universitários nacionais e estrangeiros e, ao mesmo tempo com os organismos governamentais decorrem de sua própria natureza e marcam sua especificidade. No caso dos institutos aqui analisados, os laços com os organismos estatais sempre estiveram presentes nos institutos não-governamentais como o Ibre e a Fipe e no caso do Ipea, os vínculos com os meios acadêmicos constituíram sua marca diferencial dentro do governo. $\mathrm{Na}$ verdade, as relações com as universidades nacionais e estrangeiras fizeram com que os institutos de pesquisa aplicada se caracterizassem como organizações acadêmicas e cosmopolitas, freqüientemente transformadas em espaços privilegiados de debates, como foram o Ibre, nos seus primeiros anos de existência, e o Ipea, durante o período da ditadura militar.

Os laços dos institutos de pesquisa com as universidades do exterior, em particular as americanas, e os organismos econômicos internacionais são dimensões bastante importantes a destacar. Através desses laços de intercâmbio, desenvolvidos desde os anos 40, no Ibre e reproduzidos no Ipe e na Fipe, nas décadas seguintes, os membros dos institutos de pesquisa aplicada adquiriram formação internacionalizada e relativamente homogênea, incorporando os paradigmas teóricos e orientações político-ideológicas predominantes naquelas instituições estrangeiras e internacionais. Assim, pode-se levantar como hipótese que a implementação generalizada nos anos 90, no Brasil como em outros países latino-americanos, do mesmo receituário neoliberal contido no chamado Consenso de 
Washington, pode estar associada à internacionalização dos estudos econômicos processada, ao longo de várias décadas, tanto nos meios universitários como nos institutos de pesquisa aqui analisados (LoUREIRo, 1997).

Deve-se mencionar também a questão da instabilidade institucional das agências de pesquisa, como grande parte das instituições no país e da presença aí de certos traços de relações pessoais e clientelistas. Esses institutos acabam tendo seu destino definido por contingências, tais como o peso político de um patrono que as prestigie junto aos órgãos governamentais que financiam ou demandam encomendas públicas. Assim, o maior ou menor dinamismo de cada instituição e a maior ou menor abundância de recursos aí disponíveis dependerão, em grande medida, da presença de seus membros ou antigos membros em cargos governamentais estratégicos (tanto no nível federal, estadual ou municipal). Tal presença acaba fazendo com que a instituição seja preferencialmente escolhida para trabalhos ou contratos de pesquisa com esses órgãos públicos. E, em contrapartida, as demais instituições que não contam com tal patrono vivam, neste momento, período de penúria financeira.

Por fim, cabe observar ainda que, dentre todas as atividades desenvoldias pelos diversos institutos aqui analisados, a produção e divulgação mensal dos indicadores econômicos são as que trazem maior visibilidade na imprensa para si e para seus respectivos pesquisadores. A publicação pelos jornais, não só em épocas de alta inflação, mas também em período de estabilização monetária, das estatísticas coletados por esses institutos tornam seus economistas conhecidos do grande público leitor. Eles se transformam em figuras de destaque na mídia e nos debates políticos que tais informações possam sugerir. Assim, não é por acaso que vários dos economistas que ocuparam postos de relevo em organismos governamentais, como ministros ou secretários da Fazenda, do Planejamento e vários outros, tiveram passagem pela direção dos institutos de pesquisa econômica. 
1 Expresso aqui meus agradecimentos ao CNPq e ao Núcleo de Pesquisa e Publicações (NPP), da EAESP/FGV, que financiaram partes distintas da pesquisa que permitiu a elaboração do presente texto.

2 Os bancos públicos de desenvolvimento econômico como o BNDE, o Banco do Nordeste e aqueles criados em outros estados da federação, como Paraná, Minas Gerais, etc. funcionaram também como think tanks e escolas de formação de quadros para o governo na área de planejamento econômico e desenvolvimento de projetos de investimentos. Ver a respeito do BNDE, o texto de Martins, 1984. Para o caso do Banco do Nordeste, a entrevista efetuada com o economista Nilson Holanda, que foi presidente deste banco e diretor do Ipea, é bastante clara a esse respeito.

3 Foram entrevistados sobre o Ibre: Julian Chacel, Moacir Fioravante, Paulo Cysne e Salomão Quadros. Sobre o Ipea: João Paulo dos Reis Velloso, Anibal Villela, Roberto Cavalcanti de Albuquerque, Cláudio Considera, Antonio Nilson Holanda, Sônia Rocha, Maurício Galinkin, Luís Eduardo Castelo e William de Oliveira. Sobre a Fipe, Juarez Rizzieri e Ana Maria Bianchi. Com relação ao vídeo comemorativo dos 25 anos do Ipea, foram analisados os seguintes depoimentos: Delfim Neto, Reis Velloso, Dorothéa Werneck, Mário Henrique Simonsen, Maria Conceição Tavares, João Sayad e Anibal Villela .

4 Pode-se indicar como exemplo destas novas encomendas públicas de serviços para o Ibre aquelas efetuadas por prefeituras municipais e órgãos como o Senado Federal, que buscam indicadores de custos para suas licitações. Com relação às demandas privadas, o Ibre mantém um conjunto de clientes que demandam indicadores específicos, como o IGPM, para o mercado financeiro, o cálculo da cesta básica para o Procon, antes efetuado pelo Dieese, em São Paulo, etc. 


\section{Referências bibliográficas}

BACHA, E. "Vinte e Cinco Anos de PPE". In: Pesquisa e planejamento econômico, v. 25, n.1, abril, 1985.

Bobbio, N. "Teoria das elites políticas". In: Curso de introdução à ciência política. Ed. da Universidade de Brasília, 1982.

Bottomore, T. B. “As elites e a sociedade”. Ed. Zahar, Rio de Janeiro, 1965.

Carvalho, W. A. Fundação do Ipea: formação, desenvolvimento e impasses. Ipea, 1996.

Carvalho, J. M. A construção da ordem. A elite política imperial. Ed. UFRJ e Relume Dumará. Rio de Janeiro, 1996.

Cavalcanti, R. “O Ipea e o planejamento nacional: um balanço de 25 anos”. In: Literatura econômica. Edição especial, v.1, setembro, 1989.

Chacel, J. "O Instituto Brasileiro de Economia". In: Revista Brasileira de Economia, v.20, n. 2/3, Rio de Janeiro, 1996.

Chacel, J. “O Ibre e a doutrina”. In: Conjuntura econômica, out., v. 35, n.10, 1981.

CHAcEl, J. “A FGV, o Ibre e Eu”. In: Conjuntura econômica, março, Rio de Janeiro, 1995.

CHEILUB, Z. B. "Diplomacia e construção institucional: o Itamaraty em uma perspectiva histórica”. In: Revista Dados, v.28, (1), pp.113-130.

Coelho, E. C. Em busca de identidade: O exército e a política na sociedade brasileira. Rio de Janeiro, Forense Universitária, 1976.

Dror, Y. "Required Breakthroughs in Think Tanks". In: Policy Sciences, 16: 199-225, 1984.

FAoro, R. Os donos do poder. Ed.Globo. Porto Alegre, 1975.

Geddes, B. "Building the state autonomy in Brazil, In: Comparative Politics, 22(2) jan, 1990.

GóEs, W. O Brasil do general Geisel: estudo do processo de tomada de decisão no regime militar burocrático. Nova Fronteira. Rio de Janeiro, 1978.

Gouvea, G. P. Burocracia e elites burocráticas no Brasil. Ed. Paulicéia. São Paulo, 1994.

"Ipea: O alcance de sua tarefa". In: Planejamento e desenvolvimento, 1982.

História da FEA/USP, cap. sobre o IPE/FIPE, de autoria de C.A, RoccA, E.. CeotTo e J. A. RIZZIERI, 1981.

Fipe, Currículo, 1996, USP.

JAMES, S. "The Idea Brokers: The impacts of think tanks in britain government". In: Public administration, v. 71, number 4:491-506, 1993.

JEPPERSON, R. "Institutions, institutional effects, and institutionalism”. In: Powell,W. \& DiMaggio, P.(eds.), The New Institutionalism in Organizational Analysis, The University of Chicago Press, Chicago and London, 1991.

Loureiro, M.R. Os economistas no governo. Fundação Getúlio Vargas, Rio de Janeiro, 1997.

Martins, L. Estado e burocracia no Brasil pós-64. Paz e Terra, Rio de Janeiro, 1984.

Matos, A.G., Contribuições para uma análise institucional do Ipea. Ipea, 1994.

Miceli, S. "Carne e osso da elite política brasileira pós-30”. In: Fausto (org.) História geral da civilização brasileira. O Brasil republicano III. Difel/ Difusão Editorial S/A. São Paulo, 1981.

NunEs, E. A gramática política do Brasil. ENAP/Ed. Zahar. Brasília e Rio de Janeiro, 1997.

NunEs, E. O. Legislativo, política e recrutamento de elites no Brasil. In: Revista Dados, n.17, p.53-78. Rio de Janeiro, 1978. 
Penha, E. A. A criação do IBGE no contexto da centralização do Estado Novo, documentos para disseminação, FIBGE, 1993.

Powell, W., DiMaggio, P.(eds.). The New Institutionalism in Organizational Analysis. The Universitys of Chicago Press, Chicago and London.

RIBEIRo, C. Depoimento, CPDOC, FGV, 1990.

SCHNEIDER, B.R. Politics within the state, elite bureaucrats and industrial policy in authoritarian Brazil. University of Pittsburgh press, 1991.

Schwartzman, S. Bases do autoritarismo brasileiro. Ed. Campus, Rio de Janeiro, 1988.

SiLVA, P. "Technocrats and politics in Chile: from the Chicago boys to the CIEPLAN Monks". In: Journal of latin american studies, v. 23, n. 2, 1991.

Sola, L. e Kugelmas, E. "Statecraft, instabilidade econômica e incerteza política: O Brasil em perspectiva comparada". In: Diniz, E. O desafio da democracia na América Latina. Anais de Seminário. IUPERJ. Rio de Janeiro, 1996.

SouzA, M. C. C. Estado e partidos políticos no Brasil. Alfa-Ômega. São Paulo, 1976.

Stepan, A. Os militares na política; as mudanças de padrões nas vidas brasileiras. Ed. Artenova, Rio de Janeiro, 1975.

Os militares: a abertura à Nova República. Ed. Paz e Terra. Rio de Janeiro, 1986.

Tolosa, H. "O Papel da pesquisa econômica nos vinte e cinco anos do Ipea". In: Literatura Econômica. Edição especial, v.1, setembro, 1989. 
Revista do Serviço Público

Ano 48

Número 2 Mai-Ago 1997

Socióloga, professora do curso de mestrado em administração pública e governo, da

Fundação Getúlio Vargas de São

Paulo e do Departamento de Economia da FEA/USP
Resumo

Resúmen

Abstract

\section{Formação das elites político-administrativas no Brasil: as instituições de pesquisa econômica aplicada}

Maria Rita G. Loureiro Durand

O presente estudo mostra o papel desempenhado pelas instituições de pesquisa econômica, na formação das elites administrativas encarregadas da gestão das políticas macroeconômicas no Brasil, e como elas contribuíram para a transformação de seus membros em importantes interlocutores políticos. São, assim, analisados os mais significativos organismos governamentais e não-governamentais de pesquisa econômica aplicada, como o Ibre/FGV, o Ipea e a Fipe/USP. Alguns aspectos principais se destacam. Como think tanks, isto é, agências independentes, mas produtoras de subsídios para as políticas governamentais, estes institutos são espaços intermediários entre o mundo acadêmico e o governo, aí residindo sua particularidade. Indica-se ainda a importância dos vínculos estabelecidos entre estas instituições de pesquisa, universidades americanas e organismos internacionais. Isso permitiu, relativamente, uma grande homogeneidade dos paradigmas teóricos e políticos orientadores das ações dos gestores das políticas econômicas no país, afinados com aqueles em vigor em agências como FMI, Banco Mundial, etc. Por fim, deve-se mencionar a questão da instabilidade institucional. Refletindo características mais amplas do sistema político brasileiro, as agências de pesquisa, especialmente as governamentais, têm seu destino definido por variáveis contingenciais, tais como o peso político de um patrono que as prestigie junto aos órgãos financiadores ou demandadores de encomendas públicas.

\section{La formación de las elites político-administrativas en Brasil: las instituciones de investigación económica aplicada \\ Maria Rita G. Loureiro Durand}

El presente estudio muestra el papel desarrollado por las instituciones de investigación economíca, en la formación de las elites administrativas encargadas de la gestión de las políticas macroeconómicas en Brasil, y como ellas contribuyeron para la transformación de sus miembros en importantes interlocutores políticos. De esta forma, los más significativos organismos gubernamentales y no-gubernamentales de investigación económica aplicada, como el Ibre/FGV, el Ipea y la Fipe/USP son analisados. Algunos aspectos principales se destacan. Como think tanks, es decir, agencias independientes, pero productoras de subsidios para las políticas gubernamentales, estes instítutos consisten en espacios intermediarios entre el mundo académico y el gobierno, y ahí reside su particularidad. Es indicada también la importancia de los vínculos establecidos entre tales instituciones de investigación, universidades americanas y organismos internacionales. Eso ha permitido una relativa grand homogeneidad do los paradigmas teóricos y políticos orientadores de acciones de gestores de las políticas económicas en el país, en conformidad con aquellos vigentes en agencias como el FMI, el Banco Mundial, etc. Finalmente, es necesario mencionar la cuestión de la inestabilidad institucional. Las agencias de investigación, especialmente las gubernamentales, al mostrar las características más amplias del sistema político brasileño, tienen su destino definido por variables de contingencias, tales como el peso político de un patrón que las prestigie junto a los órganos financiadores 
The formation of political-administrative elites in Brazil: institutions of research in applied economics

Maria Rita G. Loureiro Durand

The referred study examines the role played by institutions of economic research in the formation of administrative elites, in charge of the management of Brazilian macroeconomic policies, and how they can contribute to changing its members into important political interlocutors. Consequently, it analyzes the most notable governmental and nongovernmental organizations of research in applied economics, such as the lbre/ FGV, Ipea and Fipe/USP. Some important aspects are stressed, such as think tanks independent agencies that produce subsidies for governmental policies; these institutes act as intermediate grounds between the academic world and the government, where their particularity lies. The paper also indicates the importance of the bonds established between these research institutions, american universities and international organizations. ln fact, they allowed a relatively wide homogeneity of theoretical and political paradigms, which orient the actions of the managers of Brazilian economic policies, in line with those in place in agencies such as IMF and the World Bank. Finally, it should be mentioned the problem of institutional unstableness. As a reflex of broader characteristics of the Brazilian political system, research agencies, mainly the governmental ones, have their future drawn by various elements, such as the political influence of a sponsor, to give them credit among agencies that finance or demand public services. 